\title{
Transformation of a Mathematics Department's Teaching and Research Through a Focus on Computational Science
}

\author{
Yanlai Chen \\ University of Massachusetts \\ Dartmouth \\ 285 Old Westport Rd \\ Dartmouth, MA 02747, USA \\ +1 508-999-8438 \\ yanlai.chen@umassd.edu
}

\author{
Adam Hausknecht \\ University of Massachusetts \\ Dartmouth \\ 285 Old Westport Rd \\ Dartmouth, MA 02747, USA \\ +1 508-999-8322 \\ ahausknecht@umassd.edu
}

\author{
Gary Davis \\ University of Massachusetts \\ Dartmouth \\ 285 Old Westport Rd \\ Dartmouth, MA 02747, USA \\ +1 508-999-8739 \\ gdavis@umassd.edu
}

\author{
Alfa Heryudono \\ University of Massachusetts \\ Dartmouth \\ 285 Old Westport Rd \\ Dartmouth, MA 02747, USA \\ +1 508-999-8516 \\ aheryudono@umassd.edu
}

\author{
Sigal Gottlieb \\ University of Massachusetts \\ Dartmouth \\ 285 Old Westport Rd \\ Dartmouth, MA 02747, USA \\ +1 508-999-8205 \\ sgottlieb@umassd.edu
}

\author{
Saeja Kim \\ University of Massachusetts \\ Dartmouth \\ 285 Old Westport Rd \\ Dartmouth, MA 02747, USA \\ +1 508-999-8325 \\ skim@umassd.edu
}

\begin{abstract}
Undergraduate teaching that focuses on student-driven research, mentored by research active faculty, can have a powerful effect in bringing relevance and cohesiveness to a department's programs. We describe and discuss such a program in computational mathematics, and the effects this program has had on the students, the faculty, the department and the university.
\end{abstract}

\section{Keywords}

Computational science; scientific computing; undergraduate research; interdisciplinary research; transformation.

\section{INTRODUCTION}

We describe aspects of a transformation of a mathematics department that was initiated by a focus on computational science training for undergraduates and interdisciplinary research in computational science. National Science Foundation (NSF) support for this training initiative was instrumental in focusing undergraduate teaching around computational science and scientific computing, and also in assisting the development of a vision of the department as a major research and teaching over a period of four years. A significant feature of these changes is that teaching and research in scientific computing have become department in scientific computing. Execution of this vision led to some substantive changes in department structure and functioning progressively integrated one with the other, to the extent that

Permission to make digital or hard copies of all or part of this work for personal or classroom use is granted without fee provided that copies are not made or distributed for profit or commercial advantage and that copies bear this notice and the full citation on the first page. To copy otherwise, or republish, to post on servers or to redistribute to lists, requires prior specific permission and/or a fee. Copyright CJOCSE, a supported publication of the Shodor Education Foundation Inc. motivated students have manifold opportunities to carry out significant research efforts from their earliest years, and to be mentored by research active faculty and graduate students.

\section{DEPARTMENTAL DEVELOPMENT OVER 4 YEARS}

In Spring 2008 the Department of Mathematics at the University of Massachusetts Dartmouth had two active researchers in numerical analysis, and one scholar in applied linear algebra, as its entire computational mathematics group. Additionally the Department had no graduate degree (M.S. or Ph.D.) in mathematics. By Summer 2008 the Department had lost one of the active researchers in numerical analysis. Fast-forward four years to Fall 2012 and the Department had the following features:

- A five-year NSF funded training program $(\$ 789,000)$ to train mathematics undergraduates in computational science, beginning September 2008.

- Seven active researchers in scientific computing, with a focus on numerical methods for solving partial differential equations. Their areas span finite-elements methods, radial basis functions, spectral methods, multiscale methods, time discretizations, model order reduction, and uncertainty quantification. This group comprises two Full Professors one Associate Professor, and four Assistant Professors.

- Two Full Professors engaged in computational mathematics/scientific computing education research and scholarship.

- New computationally oriented mathematics courses, including a sophomore level course on scientific computing. 
- Establishment of a University Office of Undergraduate Research. One of the authors was Foundation Director of this new Office, and CSUMS-RESCUE is an exemplar program for the Office.

- A Ph.D. program in Computational Science and Engineering.

- Over \$2.5 million in competitive research, training or equipment grants over a four year period, in which Department of Mathematics faculty were PI or CoPI.

- A lead role in a University Center for Scientific Computing and Visualization Research, under the leadership of one of the authors (Gottlieb), involving partners from engineering, oceanography, and physics.

- $\quad$ A high performance computing facility, built through a partnership with mathematics and physics, and grants from the NSF and the Air Force Office of Scientific Research.

- A proposal for a BS/MS interdisciplinary program in Data Science initiated by one of the authors, sponsored by the Department of Mathematics, and supported by the Dean of Engineering and Applied Science and the University administration.

- A strong fit with the University strategic plan: the Provost and Chancellor now support Scientific Computing as a major research and training area for the University.

\section{THE NSF COMPUTATIONAL SCIENCE TRAINING GRANT}

Four faculty obtained an NSF training grant, CSUMS-RESCUE, for computational science for mathematics undergraduates. Before discussing the impact of this grant on the Department of Mathematics, we take a look at the structure and function of the undergraduate research workshops that became the visible face of the computational science program. Following that, in the next section, we examine in more detail the effect of this training grant on the structure and functioning of the Department and the University that led, in four years, to the developments described in the previous section.

\subsection{Structure of Undergraduate Research Workshops}

From the outset we conceived the CSUMS-RESCUE program as consisting of undergraduate research workshops, constructed as practical research sessions, in which students are inducted and mentored in research in computational science. We accept students into the program on the recommendation of instructors in other courses, and students at all academic levels, Freshman through Senior, are represented. Mathematics majors who work on a research project in a group with at least one other student are currently paid (approximately $\$ 18$ per hour) for a maximum of two regular semesters and one summer. Summer sessions typically last 10 weeks with 20 hours a week. Mathematics majors, students from other disciplines, and those who wish to work singly, are free to participate at any time without receiving payment. We require all participating students to have a faculty research mentor. Student mentors might be from another department - physics or engineering typically, outside of mathematics.
Students work in groups on a single project, or related projects. They are required to present short progress reports every few weeks. The final assessment is based on individual write-ups of projects, progress talks and a final presentation.

A faculty member is instructor of record for the research workshop during semester (Fall and Spring) and typically two or more other faculty, often research advisers, will be present during the workshop meeting times. One of the authors was the first instructor for the research workshops in Spring 2009 and has played a major role in their format and structure since then. Faculty who are not instructors of record do not receive not compensation during Fall and Spring. During the Summer session, faculty are allocated specific weeks in which they run the workshop and they are compensated at their regular salary levels during those weeks.

\subsubsection{A marketplace of ideas}

The format of the seminar is that of a seminar/workshop in which students regularly present accounts of ongoing research in presentations normally lasting about 10-15 minutes. This length of presentation was chosen as being representative of times allotted to talks at conferences, so giving students valuable practice in concise and informative presentations. The in-class presentations are commonly followed by questions and suggestions from other student and attendant faculty. It is during these presentations that students learn to appreciate the interdisciplinary nature of computational mathematics and scientific computation, commonly offering suggestions for new lines of investigation, new computational techniques, or new ideas for consideration. The cohesion of the cohort is built in part by the regular interchange of results, approaches, and ideas. Additionally, students commonly work on their research projects during the computational seminar time, and will regularly walk around and join with other students to see what they are doing, and offer help and suggestions. The atmosphere of the seminar is best described as a market place of ideas and techniques where faculty present work to build an atmosphere of interest and respect across widely differing computational mathematics projects. Seeking common ground, and finding computational techniques and analyses that extend across these different applications has been a major goal of the seminar, and students quickly buy into this interdisciplinary approach.

\subsection{Recruitment}

Recruitment of students into the research workshop was initially through recommendations from instructors in other courses, especially early calculus courses. A group of three faculty - the PI and a Co-PI for the NSF grant, as well as the Director of Consulting \& Data Management for the project - formed the admissions committee. When an instructor identified a promising student in their class they would talk with one or more members of the admissions committee who would most commonly interview the recommend student and ascertain their interests as well as existing or likely research advisers. When the program had been running for some semesters it was not uncommon for students to hear about it by word of mouth and come looking for a member of the admissions committee to see if the experience was right for them. Considerable effort was put into recruiting underrepresented minorities in computational science, particularly women and African-American students. 


\subsection{Building a Cohort}

The CSUMS program was designed to maximize the opportunities for peer support and collaboration. To this end, our students present their work to each other and become involved in each other's projects. The reliance on MATLAB, Mathematica, Python, and Latex requires our students to work together and collaborate with each other, and the relaxed atmosphere in the computer classroom encourages the students to talk, ask, answer, and generally communicate well. Some of our students have done their best work in pairs. For example in the 2009 Summer workshop, two students worked together on coordinate metrology, two on collocation methods, aliasing, and the Runge phenomenon, with another student joining them for parts that overlapped with her research interests in wavelets and Fourier analysis. Two students formed a strong team, centered on their interest in cryptography, and presented a joint paper at the SIAM annual meeting. In addition, another student and a graduate student spent a lot of time on the implementation of MPI and parallel Python on the computers in the room. We consistently try to match up students to work on the same or similar topics, but this does not always match their interests and research style. Students talk to each other, learn from each other, challenge and advise, write summaries and code together and debug each other's work. It is difficult to describe how we measure success in forming a cohesive cohort. One indication is the fact that our students decide to take the same sections of courses, they prefer to stick together and they discuss their projects outside of the CSUMS environment. Another indicator of success is the atmosphere in the computer room. It is a dynamic, exciting, collaborative atmosphere, which is fun to be in. The faculty like the atmosphere so much that they often hang out there and have impromptu meetings and talks.

\subsection{Enrolment Numbers}

The National Science Foundation supported research training workshops in computational science began Spring 2009 and will continue under this funding model until Summer 2013. To date, 70 students have participated in these workshops, several of them for 3 semesters, and a few returning, unpaid, for another semester. Table 1, below, lists the enrolment numbers from Spring 2009 through Fall 2012.

Table 1. Research training workshop enrolments

\begin{tabular}{|l|l|}
\hline Semester & \# students \\
\hline Spring 2009 & 15 \\
\hline $\begin{array}{l}\text { Summer } \\
2009\end{array}$ & 12 \\
\hline Fall 2009 & 18 \\
\hline Spring 2010 & 8 \\
\hline Fall 2011 & 12 \\
\hline Spring 2012 & 9 \\
\hline $\begin{array}{l}\text { Summer } \\
2012\end{array}$ & 8 \\
\hline
\end{tabular}

\begin{tabular}{|l|l|}
\hline Semester & \# students \\
\hline $\begin{array}{l}\text { Summer } \\
2010\end{array}$ & 11 \\
\hline Fall 2010 & 11 \\
\hline Spring 2011 & 16 \\
\hline $\begin{array}{l}\text { Summer } \\
2011\end{array}$ & 11 \\
\hline Fall 2012 & 8 \\
\hline Spring 2013 & 16 \\
\hline $\begin{array}{l}\text { Summer } \\
2013\end{array}$ & 9 \\
\hline
\end{tabular}

\subsection{Conference Participation}

Funding from the NSF has meant that funded students are able to travel, at no cost to themselves, to regional and national conferences and to participate in those conferences as active participants, presenting posters on their research, or delivering talks or refereed papers, or as interested observers.

Each April students are strongly encouraged to present posters or talks at both the Massachusetts Statewide Undergraduate Research Conference at the University of Massachusetts Amherst, and at the University of Massachusetts Dartmouth Sigma Xi Exhibition. Additionally, students participating in the Summer research workshops are encouraged to attend and, where possible, participate through poster presentations or talks in the annual conference of the Society for Industrial and Applied Mathematics (SIAM). Students were also strongly encouraged to participate in local, national and international meetings and conferences. Some details are shown below in Table 2 .

Table 2. Number of students attending Summer conferences

\begin{tabular}{|c|c|c|}
\hline Year & Summer Conference & \#students \\
\hline \multirow[t]{2}{*}{2009} & $\begin{array}{l}5^{\text {th }} \text { MIT Conference on Computational } \\
\text { Fluid and Solid Mechanics }\end{array}$ & 12 \\
\hline & SIAM Annual Meeting, Denver, CO & $4+1 \mathrm{grad}$ \\
\hline 2010 & $\begin{array}{l}\text { Northeast Section of the Mathematical } \\
\text { Association of America, Salve Regina } \\
\text { University, Newport, RI, }\end{array}$ & $8+1 \operatorname{grad}$ \\
\hline 2010 & SIAM Annual Meeting, Pittsburgh, PA, & $9+1 \operatorname{grad}$ \\
\hline \multirow[t]{2}{*}{2011} & $\begin{array}{l}\text { NSF-CBMS Radial Basis Function } \\
\text { Conference, UMass Dartmouth, Fall } \\
\text { River, MA }\end{array}$ & 11 \\
\hline & $\begin{array}{l}\text { 7th International Congress on Industrial } \\
\text { and Applied Mathematics, Vancouver, } \\
\text { BC, Canada }\end{array}$ & 9 \\
\hline 2012 & $\begin{array}{l}\text { SIAM Annual Meeting, Minneapolis, } \\
\text { MN }\end{array}$ & 10 \\
\hline 2013 & $\begin{array}{l}\text { SIAM Annual Meeting, San Diego, } \\
\text { California, USA. }\end{array}$ & 9 \\
\hline
\end{tabular}

\subsection{The Summer Experience}

The Summer research workshops were more intensive than those during Fall and Spring semesters. Students meet 12:00 PM - 5:00 PM Monday-Thursday for 10 weeks during the Summer. This intensive experience has proved most helpful in introducing students to the research experience and mentoring them in their first steps in research. The semester classes were held Tuesdays and Thursdays for 75 minutes per class, for a total of 15 weeks. Not only were the students in Summer getting 5 times the in-class research exposure, they were also getting it in more concentrated form. As a result, we found that students who began research experiences in computational mathematics in the Summer generally stuck with their research projects better than students who began in the Fall or Spring semesters.

\subsection{Effect on Students}

The question of how an intensive and sustained research experience for undergraduates affects individual students has been tackled in several studies. Kardash [1] reports that an undergraduate research experience can enhance skills differentially; Seymour et al. [2] report, in a study of undergraduate science research, that an overwhelming majority of participants experienced positive gains, including areas such as: "thinking and working like a scientist; clarification/confirmation 
of career plans (including graduate school); and enhanced career/graduate school preparation (9\%)". Hunter et al. [3] found that in relation to undergraduate scientific research, faculty focused on gains related to apprenticeship in scientific research while students focused more on skills development.

\subsubsection{Surveys}

A Likert attitude survey was administered to participating students toward the end of the spring 2009 semester. Significant are the questions with a high $(>1)$ or low $(<-1) \mathrm{z}$-score. We infer from answers to questions with a high or low $\mathrm{z}$-score, that students, on average:

- $\quad$ liked having external speakers;

- found it helpful to be with a group of students from different backgrounds;

- $\quad$ learned a lot about their chose research topics by being part of the CSUMS cohort;

- found the faculty who attended the seminar to be helpful and appreciated the style of interaction;

- learned a lot about computation and programming;

- felt comfortable approaching faculty to advise them;

- found seminar presentations by students to be important;

- $\quad$ agreed with the emphasis on MATLAB;

- did not want student talks restricted to 10 minutes;

- felt that students with less than high GPAs should also be recruited to the program;

- $\quad$ were comfortable with giving external presentations;

- $\quad$ did not find presenting stressful;

- appreciated the diversity of interests of student participants.

This survey provides evidence that the cohort structure of the program is a beneficial feature.

A 2010 survey of students indicated that students rate giving inclass presentations positively, scoring 4.35 on a 5 point scale, ranging from Very Negative to Very Positive, when asked: "Please rate your overall experience of talking in class. My overall experience of giving in-class talks is that it has been, for me personally: [Very Negative through Very Positive] "

Comments included:

- This greatly improved my confidence in public speaking.

- I have gained valuable experience for speaking in class. I have learned from the CSUMS group on how to better my presentations.

- $\quad$ Great feedback. Excellent direction from Professors and Students alike.

- Personally, I get very nervous giving talks, but with each presentation it does seem easier, and when you know your research well, talks can be a very good way of getting feedback. Talks also make you rethink and understand your work better, in order to allow the audience to understand.

- Although nerve-racking at first, class presentations helped make in the long run. It improved my public speaking skills, but also when explaining the material it really let me know what I needed to re visit to get a better understanding. Plus it was a good way to see what everyone else was working on, and learn some new things.

- For me, all the presentations and talk helped me to improve my presentation skill for my later profession. Feedback is always very helpful and a lot of the questions asked really help me understand my projects even better.

\subsection{Productive Outcomes}

A significant effect on participating students has been a realization that research, unlike course-work, is often messy, with numerous backtracks and changes of direction. Students have come to realize that their professors and mentors do not always know everything and that learning through research is a partnership. Faculty members, for their part, have been willing to trust students, even those with relatively modest achievements in mathematics, to find their way through a research problem with advice and mentoring. A very telling example of this is a young man who worked on fitting normal inverse Gaussian distributions to distributions of percentage obesity by U.S. county for the years 2004-2009. His mathematics achievements prior to this were modest. Yet, motivated by the research topic he chose, and mentored and assisted by two faculty members, he learned how to practically implement maximum likelihood methods for complicated parametric distributions, and to use those to say something statistically important about the data. With the two faculty members, this student is in the process of writing up his research for publication. Other, more mathematically talented students have written professional research papers with their faculty mentors, and others have been stimulated to seek summer research experiences elsewhere, following their CSUMSRESCUE experiences. Some, who went on to quantitative research environments, have written to us to say how important were the technical skills they learned during their time in the computational science research workshops. These skills included programming skills - MATLAB and Python particularly - data analysis skills and statistics more generally, linear algebra, writing in LaTeX and Beamer, and presentation skills.

\subsection{Less Productive Outcomes}

Not all student experiences in the CSUMS-RESCUE program were as positive as the faculty would have liked them to be. Some of the issues that arose over the period the program has been funded by NSF include:

- Students who, despite being paid, did not engage with their research topics. Such students were more likely to have been admitted to the program as part of a group, and agreed to the project as part of that group, without being fully motivated to carry out research.

- Students who consistently did not listen carefully to other student presentations, either working on a computer or idly staring out a window.

- Some highly mathematically talented students, who see their mathematical career in teaching, are not amenable to thinking computationally about mathematical problems and generally do not like programming.

- Students who, despite heroic efforts on the part of participating faculty, just were not able to show the necessary technical ability, skills, or attitude to carry out computational science research projects.

This last point has several aspects to it, and requires further study and elucidation, in our view. While all faculty are delighted to find exceptionally talented students who soar when exposed to a research environment, we have an educational mission to productively educate all students, and a belief that undergraduate research can be empowering for a majority of students, and can and should be integrated into the undergraduate curriculum, in line with a 1989 NSF report [4]. 
Additionally, one of us (Davis) tried unsuccessfully for several summers to run computational science training workshops for local high school teachers. The work of Jacobs et al [5] has recently come to our attention, and the programs described there may be helpful in this regard.

\section{EFFECT OF THE COMPUTATIONAL SCIENCE TRAINING GRANT ON THE DEPARTMENT AND THE UNIVERSITY}

\subsection{Effect on the Department}

\subsubsection{New Faculty}

The NSF computational science training grant played a significant role in focusing the entire Department on computational mathematics and computational science. In the Fall of 2008 two new appointments were made in numerical analysis at the Assistant Professor level. This brought to three the number of active researchers in numerical analysis. Since then new tenuretrack faculty appointments have all been in the area of computational mathematics, with 3 additional faculty appointed as of 2012. Additionally, another faculty member changed her research from commutative algebra to computational applied mathematics, and obtained promotion to Full Professor on the basis of her new research.

\subsubsection{External Review}

An AQAD external review of the Department of Mathematics was conducted in 2009. The reviewers commented on the CSUMSRESCUE program as follows:

"A most notable, very recent development in this area has been the Research in Scientific Computing in Undergraduate Education (RESCUE) project ... It would be hard to overstate the positive impact of this activity. The major concrete outcomes have been a program of undergraduate student research projects and a seminar course in which students present the results of their projects. These provide excellent vehicles for obtaining "handson" experience applying modern mathematical and computational methods to real-world problems and making presentations on the results. During our visit, we attended a seminar session during which several students gave presentations about their research projects. We were very impressed by the timely mathematical content and societal relevance of the projects presented, as well as the overall polish of the presentations. In a later meeting with a group of students, most of whom participated in RESCUE, we heard strong words of praise and appreciation for the program. Students liked working on projects that interested them, enjoyed the close working relationships with faculty advisors, and appreciated the funding (up to 10 hours of work per week) provided by the grant to participate in the project. (One student said that the funding allowed her to quit her second part-time job.) We also observed that RESCUE appears to involve many faculty members, including a number who were not originally involved in the RESCUE grant proposal. Indeed, seven faculty members meet every other week to work together on this project. Our summary opinion is that the RESCUE project has become a centerpiece of the department's programs that appeals to both students and faculty and that is helping greatly to add cohesiveness and relevance to the department's programs."

\subsubsection{Research Advisers}

With only two exceptions, faculty in the Department of Mathematics, have been research advisers to students in the computational science program. As faculty increased in numbers, at least six faculty were actively involved in semester and Summer workshops - advising students, overseeing their work and mentoring them through the research process.

Many students were interested in research topics for which the principal, often sole, adviser was a faculty member in Engineering or Physics. This had an effect of bringing faculty in Engineering, Mathematics and Physics with a computational science interest closer together. Faculty from Engineering Departments and Physics gave computationally oriented talks to undergraduate students. Faculty in Mathematics gave talks on software development to the undergraduate students, to which faculty from other Departments occasionally attended. Gradually, a spirit of cooperation over research advising, more general research projects, and attendance at seminars in other Departments became common. Undergraduate students in the computational science program are expected and encouraged to attend research presentations from speakers from outside the University.

\subsubsection{New and Modified Courses}

In 2007 one of the authors (Hausknecht) introduced a course on Scientific Programming as an upper level course. For the early versions of the course he used Java, Octave and TEMATH [6]. He learned about Visual Python from an ICTCM talk he attended, and switched to Python for the following reasons:

- The potential of Visual Python to graphically illustrate ideas of computational mathematics;

- Many mathematicians and scientists were using Python as an open source replacement for MATLAB;

- $\quad$ Python can be used for general computing including gluing together programs written in FORTRAN and C;

- Many people find Python easier to learn than other languages.

One of the authors was also motivated by the Department's shift to numerical/applied mathematics, which became more focused with the advent of the CSUMS-RESCUE program.

After trialing for several semesters at the upper level the course on Scientific Computing has now been institutionalized as a sophomore level offering for all mathematics students. The course description includes:

"Calculus-based programming covering conditionals, loops, arrays, file I/O, libraries, data types, and operating system commands. This course provides a project driven introduction to programming using a selection of mathematics programming tools, scripting languages, and traditional languages ..."

Calculus 2 is a pre-requisite for the Scientific Programming course, and either Calculus 3, Differential Equations, or Linear Algebra is a co-requisite. The purpose of these pre- and corequisites is to restrict enrolment in this sophomore level course to students with a strong enough mathematical background, and continuing study in mathematics, to be able to cope with the scientific examples used in the course.

To a large degree this course in Scientific Programming fulfills the mathematics major requirements for a computing course, and is one that is more clearly directed to mathematics majors. Recently the Department of Physics has decided to use this course as a preferred training for students in programming that is more closely aligned to physics majors.

Additionally, several courses including differential equations, mathematical modeling, numerical analysis, and mathematical statistics have been revised to include a computational emphasis. 
In Spring 2012 one of us (Heryudono) designed and taught a graduate level course in High Performance computing, using MATLAB as a high level language to access a high performance computer cluster. The experiences of Shiflet \& Shiflet [7] indicate that such a course could also be accessible to undergraduates.

\subsection{Effect on the University}

The CSUMS-RESCUE solidified ties for faculty particularly in Engineering Departments, Mathematics, and Physics, with some input from Biology and Chemistry. Faculty from different Departments talked more about research, including research plans. An atmosphere developed in which collaboration seemed not only possible but genuinely desirable. An issue that had been on the mind of one of the authors (Gottlieb) for some time now seemed eminently possible, and so the Scientific Computing Group [8] was born which led very rapidly to University approval for a Center for Scientific Computing and Visualization Research, with very strong support and input from the Dean of Engineering and Applied Science. A result of this growth is the alignment of the Department of Mathematics with the University strategic plan in which computational mathematics and scientific computing more generally, are a central part of that plan.

\section{CONCLUSIONS}

An embryonic computational mathematics group was in danger of slipping away without a plan and vision for the future. Faculty worked on the CSUMS-RESCUE training grant which, as the Department's external reviewers stated: “... has become a centerpiece of the department's programs that appeals to both students and faculty and that is helping greatly to add cohesiveness and relevance to the department's programs." That cohesiveness and relevance picked up steam through a focused faculty recruitment plan, the establishment of a Center for Scientific Computing and Visualization Research, a Ph.D. program, establishment of a University Office of Undergraduate Research, developments in Data Science through a proposed $\mathrm{BS} / \mathrm{MS}$, and marked improvement in competitive research and training grants.

Research and teaching in the Department are now more integrated than they were four years ago. Students who participate in the research training program are in regular contact with research active faculty and graduate students. The number of students participating in the computational science research program in a given semester is a relatively small percentage of the total number of mathematics majors. However, students can participate in the research program any time from the second semester of their Freshman year (after completing Calculus 1) up to their Senior year, students have a total of 10 semesters (including summers) in which to participate. This means the program has impacted a significant percentage of mathematics majors to date. Teaching mathematics, for almost all tenured and tenure/track faculty has become more focused on computation and on research opportunities for students.

The computational science research training program is institutionalized in the Department. How strong student participation will be once NSF funding is no longer available remains to be seen. Establishment of an Office of Undergraduate
Research in the University has lead to a fund-raising effort for undergraduate research in general, and a focus on the importance of undergraduate research in the curriculum for which the CSUMS-RESCUE program is an exemplar. The establishment of a Ph.D. program in Computational Science and Engineering, a Center for Scientific Computing and Visualization Research, and a planned Data Science BS/MS program, have all extended and solidified the opportunities for undergraduate students to become deeply involved in serious scientific research in computational science as part of their normal undergraduate experience.

\section{ACKNOWLEDGMENTS}

This work was supported by National Science Foundation grant DMS- 0802974 "RUI: CSUMS: Research in Scientific Computing in Undergraduate Education (RESCUE)". The views and opinions expressed here are those of the authors and do not reflect or represent the views of the National Science Foundation.

We acknowledge the strong support of Robert Peck, Dean of Engineering and Applied Science at the University of Massachusetts Dartmouth.

\section{REFERENCES}

[1] Kardash, C.M. 2000. Evaluation of an undergraduate research experience: Perceptions of undergraduate interns and their faculty mentors. Journal of Educational Psychology, 92(1), 191-201.

[2] Seymour, E., Hunter, A., Laursen, S.L. and DeAntoni, T. 2004. Establishing the benefits of research experiences for undergraduates in the sciences: First findings from a threeyear study. Science Education, 88(4), 493-534.

[3] Hunter, A., Laursen, S.L. and Seymour, E. 2007. Becoming a scientist: The role of undergraduate research in students' cognitive, personal, and professional development. Science Education, 2007, 91(1), 36-74.

[4] National Science Foundation. 1989. Report on the National Science Foundation disciplinary workshops on undergraduate education. Washington, DC.

[5] Jacobs, P. and Houchins, J. 2012. Building a project methodology to provide authentic and appropriate experiences in computational science for middle and high school students. Journal of Computational Science Education, 3(1), 11-18.

[6] Hausknecht, A. O. and Kowalczyk, R. E. TEMATH (Tools for Exploring Mathematics) http://www.faculty.umassd.edu/adam.hausknecht/temath

[7] Shiflet, A.B. and Shiflet, G.W. 2010. Testing the waters with undergraduates (If you lead students to HPC, they will drink). Journal Of Computational Science Education, 1(1), 33-37.

[8] UMass Dartmouth Scientific Computing Group. http://umassdcomputing.org 